Sir,

\section{Response to Banerjee et al}

We read with keen interest the letter by Banerjee $e t$ al ${ }^{1}$ titled 'Routine use of topical cyclopentolate as a predisposing factor to recurrent urinary tract infections in a susceptible adult'. As highlighted, cyclopentolate eyedrops can have serious systemic effects, more so in children. We just wish to highlight that it should be used with caution in children. Some of the methods to decrease the chances of toxicity include avoiding overdosage, punctal occlusion following application, and avoiding high ambient temperature and humidity $^{2}$. The use of microdrops $(5 \mathrm{ml})$ as compared with normal drops $(35 \mathrm{ml})$ could also reduce the incidence of side effects ${ }^{3}$. Other options include diluted cyclopentolate or safer drugs such as tropicamide and homatropine (2\%).

\section{Conflict of interest}

The authors declare no conflict of interest.

\section{References}

1 Banerjee PJ, Elgohary MA, Charteris DG. Routine use of topical cyclopentolate as a predisposing factor to recurrent urinary tract infections in a susceptible adult. Eye 2013; 27: 676.

2 Lyndon WJ, Hodes DTT. Possible allergic reactions to cyclopentolate hydrochloride: case reports with literature review of uses and adverse reactions. Ophthalmic Physiol Opt 1991; 11: 16-21.

3 Gray LG. Avoiding adverse effects of cycloplegics in infants and children. J Am Optom Assoc 1979; 50: 465-470.

$\checkmark$ Pooniya' and N Pandey ${ }^{2}$

${ }^{1}$ Department of Pediatrics, 155 Base Hospital, New Delhi, India

${ }^{2}$ Department of Pediatrics, Rohilkhand Medical

College, Bareilly, India

E-mail: nishaimsbhu@gmail.com

Eye (2013) 27, 677; doi:10.1038/eye.2013.30; published online 1 March 2013

\section{Sir, \\ Comment on: How common is inflammatory marker-negative disease in giant cell arteritis?}

We read with interest the report by Dr Levy and colleagues $^{1}$ about a case of giant cell arteritis (GCA) with normal C-reactive protein (CRP). The studies reviewed by the authors indicate that this is an unusual finding. However, the authors' inadvertent omission of two recent articles evaluating laboratory predictors of a positive temporal artery biopsy is potentially misleading. ${ }^{2,3}$ The study by Parikh et al ${ }^{4}$ used a much lower cut-off for normal CRP of $5 \mathrm{mg} / \mathrm{l}$, which may be the reason for the high sensitivity of CRP reported in their study. In the study by Walvick and Walvick, ${ }^{2}$ a CRP cut-off of $5 \mathrm{mg} / 1$ yielded a sensitivity of $94.9 \%$, which means that $5.1 \%$ had a falsely normal CRP (less than $5 \mathrm{mg} / \mathrm{l}$ ). In our study of 764 patients who underwent temporal artery biopsy, the sensitivity of CRP for GCA was $86.4 \% .^{3}$ In other words, $13.6 \%$ patients had a normal CRP (less than $8 \mathrm{mg} / \mathrm{l}$ in our laboratory), a much higher percentage than previously reported. Therefore, normal CRP does not exclude GCA in a patient with high clinical suspicion such as the case reported by Levy and colleagues. ${ }^{1}$ We would also suggest that the case reported by Levy and colleagues ${ }^{1}$ had an elevated erythrocyte sedimentation rate (ESR) and therefore would more appropriately be considered 'CRPnegative' rather than 'inflammatory marker-negative disease'. True 'inflammatory marker-negative disease' (ie, both ESR and CRP normal) is rare but was observed in $4 \%$ (seven patients) in our study. ${ }^{3}$ In summary, the currently available biomarkers for diagnosis of GCA (ie, ESR and CRP) are imperfect given the less than desired sensitivity and poor specificity. Additionally, while studies evaluating these biomarkers provide us with aggregate results about a group of patients, they remain suboptimal when considering an individual patient presentation. Regardless of laboratory evaluation, in patients with high clinical suspicion for GCA we believe a temporal artery biopsy should be pursued as was done by Dr Levy and colleagues ${ }^{1}$ to establish the diagnosis.

\section{Conflict of interest}

The authors declare no conflict of interest.

\section{Acknowledgements}

Dr Kermani was supported by the Vasculitis Clinical Research Consortium (VCRC), which has received support from the National Institute of Arthritis and Musculoskeletal and Skin Diseases (U54AR057319), the National Center for Research Resources (U54 RR019497), and the Office of Rare Diseases Research. The VCRC is part of the Rare Diseases Clinical Research Network (RDCRN).

\section{References}

1 Levy SL, Bull AD, Nestel AR. How common is inflammatory marker-negative disease in giant cell arteritis? Eye 2012; 27(1): 106-108

2 Walvick MD, Walvick MP. Giant cell arteritis: laboratory predictors of a positive temporal artery biopsy. Ophthalmology 2011; 118(6): 1201-1204.

3 Kermani TA, Schmidt J, Crowson CS, Ytterberg SR, Hunder GG, Matteson EL et al. Utility of erythrocyte sedimentation rate and C-reactive protein for the diagnosis of giant cell arteritis. Semin Arthritis Rheum 2012; 41(6): 866-871.

4 Parikh M, Miller NR, Lee AG, Savino PJ, Vacarezza MN, Cornblath $\mathrm{W}$ et al. Prevalence of a normal C-reactive protein with an elevated erythrocyte sedimentation rate in biopsy-proven giant cell arteritis. Ophthalmology 2006; 113(10): 1842-1845.

\section{TA Kermani $^{1}$ and KJ Warrington ${ }^{2}$}

${ }^{1}$ Division of Rheumatology, David Geffen School of Medicine at University of California Los Angeles, Los Angeles, CA, USA 
Division of Rheumatology, Mayo Clinic, Rochester, MN, USA

E-mail: kermani.tanaz@yahoo.com

Eye (2013) 27, 677-678; doi:10.1038/eye.2013.19; published online 8 March 2013

\section{Sir}

Response to Comment on: How common is inflammatory marker-negative disease in giant cell arteritis?

We thank Dr Kermani et al ${ }^{1}$ for their interest in our article.

In response to their comments on our report ${ }^{2}$ we acknowledge the inadvertent omission of two recent articles, ${ }^{3,4}$ both of which emphasise the occurrence of CRP-negative disease seen in giant cell arteritis (GCA). Our case is clearly described as 'CRP-negative disease', and in addition to this we review inflammatory-markernegative disease in GCA, as it is appropriate and informative in this context.

The threshold for an abnormal CRP result is ill defined. Indeed various receiver operating characteristic curves for CRP have been published, illustrating the trade-off of sensitivity and specificity at various threshold settings. Also, different laboratories express the parameter as either $\mathrm{mg} / \mathrm{l}$ or $\mathrm{mg} / \mathrm{dl}$, which can be a source of confusion in clinical practice. Hayreh et $a l^{5}$ use a level $<24.5 \mathrm{mg} / 1$ $(2.45 \mathrm{mg} / \mathrm{dl})$ as a cut-off for normal in the context of GCA.

\section{References}

1 Kermani TA, Warrington KJ. Comment on: How common is inflammatory marker-negative disease in giant cell arteritis? Eye 2013; 27: 677-678

2 Levy SL, Bull AD, Nestel AR. How common is inflammatory marker-negative disease in giant cell arteritis? Eye 2013; 27(1): 106-108

3 Walvick MD, Walvick MP. Giant cell arteritis: laboratory predictors of a positive temporal artery biopsy. Ophthalmology 2011; 118(6): 1201-1204.
4 Kermani TA, Schmidt J, Crowson CS, Ytterberg SR, Hunder GG, Matteson EL et al. Utility of erythrocyte sedimentation rate and C-reactive protein for the diagnosis of giant cell arteritis. Semin Arthritis Rheum 2012; 41(6): 866-871.

5 Hayreh SS, Podhajsky PA, Raman R, Zimmerman B. Giant cell arteritis: validity and reliability of various diagnostic criteria. Am J Ophthalmol 1997; 123(3): 285-296.

\section{SL Levy ${ }^{1}, A D$ Bull ${ }^{2}$ and AR Nestel ${ }^{3}$}

${ }^{1}$ Ophthalmology Department, Royal Hallamshire Hospital, Sheffield, UK

${ }^{2}$ Histopathology Department, North Devon District Hospital, Barnstaple, UK

${ }^{3}$ Ophthalmology Department, North Devon District

Hospital, Barnstaple, UK

E-mail: sarahfoster@doctors.org.uk

Eye (2013) 27, 678; doi:10.1038/eye.2013.20; published online 8 March 2013

Sir,

An unusual case of orbital cellulitis

Orbital cellulitis is an ophthalmic emergency that may lead to both life- and sight-threatening complications. We report the case of a child who presented with orbital cellulitis secondary to self-inflicted periocular and facial lacerations during sleep. He regained normal visual function after propitious ophthalmic and psychiatric intervention.

\section{Case report}

A 6-year-old boy presented with a 2-day history of painful protrusion of the left eye.

On examination, multiple fresh and old scratch marks were seen over his face. The left eye showed lacerated wounds on the lids, axial proptosis, ptosis, and conjunctival chemosis (Figure 1). Vision was 6/12. Extraocular movements were restricted. Pupils and retinal examination were normal. Computerized
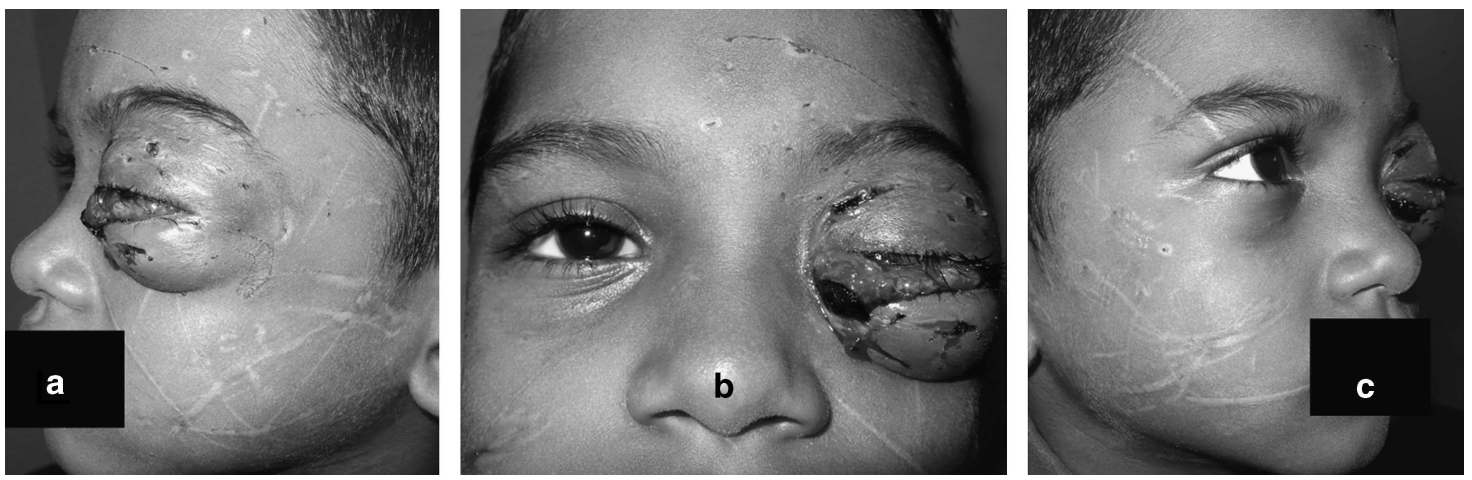

Figure 1 Clinical photographs showing (a) right lateral; (b) frontal; (c) left lateral views of the patient with facial scratch marks and left eye ptosis, proptosis, and periocular lacerations. 